\title{
Practical tailings slurry dewatering and tailings management strategies for small and medium mines
}

\author{
GI McPhail Water, Waste and Land Australia Pty Ltd, Australia \\ R Ugaz Water, Waste and Land Australia Pty Ltd, Australia \\ F Garcia Dewatering Technologies Australia, Australia
}

\begin{abstract}
Recent tailings facility failures and the resulting emphasis on ensuring that the best available technology is applied when designing a tailings management system, together with a need to reduce water consumption, have brought about a need for wider evaluation of tailings management approaches. A key determining issue is the extent to which tailings slurry can be cost-effectively dewatered. This issue often drives the selection between high-density slurry, paste and filtered tailings management approaches. Commonly, the focus is purely on thickening, where production rates exceed 30,000 t per day, or filtration, which is most suitable for production rates below 30,000 t per day due to the number of units required, as the means for separating the solids and the liquids. However, there are alternative approaches, suitable for small and medium sized mines, that are not only competitive in terms of capital and operating cost but that may also be significantly more robust and accommodating of variations in ore mineralogy and process plant upsets. These entail the application of hydrocyclones and/or vibratory dewatering screens in conjunction with thickening and/or filtration, sometimes treating only a part of the tailings stream in order to more reliably achieve dewatering targets. The alternative approaches can facilitate more balanced optimisation between the broader drivers of water recovery, slope stability, seepage control and post-closure relinquishment. This paper describes a range of alternative dewatering approaches (in addition to pure thickening or filtration) that merit consideration. It provides insight into the methods of testing and evaluation for selection and sizing of the equipment, describes tailings placement and storage methods associated with varying degrees of dewatering, and discusses the related benefits in terms of robustness of dewatering, water recovery, slope stability, seepage control and post-closure relinquishment.
\end{abstract}

Keywords: tailings dewatering, solid-liquid separation, high-density slurry

\section{Introduction}

In hydrometallurgical extraction processes, by definition, the medium for extraction is water mixed with reagents, and the residues from these processes (tailings) are usually in slurry form. In addition to providing a means for bringing the reagents into contact with the ore, water is a convenient and efficient means for mobilising dissolved and undissolved solids through the extraction process. The water with residual reagents is also an efficient means for transporting the tailings to a tailings storage facility (TSF) and distributing the tailings around as well as into the TSF. However, the water becomes a nuisance and a hazard, and is good only for suppressing wind-blown dust from the surface of the deposited tailings.

Issues generated by the water in the deposited tailings relate to:

- Supernatant water released by the tailings on sedimenting-out that needs to be controlled to minimise the risk of overtopping the crest of the TSF.

- Interference with the densification and shear strength development of the sedimented tailings mass. 
- Slope instability due to pore water pressures generated by the flow of stored supernatant water and rainwater as this moves from the surface of the TSF to the toe of the TSF.

- Surface as well as groundwater contamination control, which usually necessitates the use of filter drains and liners.

Up until the 1940s, slurry was pumped directly from the processing plant to the TSF, which formed the primary solid-liquid separation or dewatering facility. However, with increasing production rates and lower ore grades, the issues that have been noted (together with a realisation that the water contains not only valuable reagents that can be reused but also potentially recoverable dissolved metal that has been dissolved at great cost considering the mining, crushing, milling and processing efforts expended) brought about more concentrated efforts at recovering the water as close to the processing plant as practicable. The result was the development of clarifiers. These clarifiers became thickeners with the advent of polymers to improve flocculation of the fine and colloidal fractions of the tailings mass, and solids concentrations progressively increased from 15 to $25 \%$ solids by mass to 45 to $55 \%$ by the 1960s. These concentrations became the 'new normal' until the 1980 s when increasing public awareness of the scale of disasters that can result from failure of TSFs, together with greater environmental awareness, began to drive dewatering technology further up the solids concentration scale resulting in the development of high rate, high-density and paste thickeners capable of lifting solids concentrations above $60 \%$ and up to $72 \%$ by weight, respectively.

But industry experience with thickening to these high concentrations has met with generally poor success. Part of this is due to the need for design methods to catch up with design demands but part also is due to economics and the cost of thickeners that increases dramatically with increasing size and capacity. The situation is made worse by operator fears of 'bogging' a thickener and hence their tendency to operate at solids contents lower than the design concentration.

Worldwide, there is a near frenetic rate of development of slurry dewatering methods that are able to overcome these issues with thickeners. The pace of development is being fanned by recent prominent failures of TSFs and the reaction of regulators, the public and professionals. The pendulum has swung heavily towards 'dry' disposal of a tailings 'cake' that can be compacted into place but the capital and operating costs of dry disposal, particularly on large-scale mines, are proving to be major challenges. Apart from dewatering costs, mechanical transport and placement of tailings is proving costly. Dry disposal needs very significant safety and environmental drivers for justification. Certainly, in desert areas, or where sea water has to be pumped to elevations over $1,500 \mathrm{~m}$, or in mountainous areas where hydraulic deposition is unwieldy and stability issues are a real concern, or in seismic regions, these drivers exist and today a number of major projects are considering dry disposal as the only practical means of controlling tailings management risks.

However, the cost-benefits of hydraulic transport and placement of tailings remain attractive and many more projects are considering high-density slurry disposal as a realistic trade-off between water savings, increased stability and slurry dewatering costs.

Since the advent of the Australian Centre for Geomechanics' (ACG) Paste and Thickened Tailings Seminars some 20 years ago, the maxim has been to design the tailings slurry management system from the TSF backwards to the plant. This remains a valid approach, particularly if the design process begins with the question of 'what do we want to leave behind such that the issues of long-term liability, nuisance and maintenance are minimised?'. Beginning some seven to ten years ago, the seminars have been expanded to include methods of dewatering to a cake as well as associated dry TSF management requirements but, as with most technologies, the approaches quickly come down to one or two dominant approaches as a result of development cost and practicality. Today, the focus is on high rate, high-density and paste thickening as well as pressure or vacuum filtration.

However, there are other approaches, some of which are based on well-established technologies that have been proven to be robust and have relatively low capital and operating cost bases. These approaches are the focus of this paper. 
Two approaches, as noted in McPhail (2015), are hydrocyclone dewatering and vibratory screen dewatering. These approaches are explored further in this paper.

\section{$2 \quad$ Hydrocyclones for slurry dewatering}

Hydrocyclones, or cyclones, as they are commonly called, have long been in use for slurry classification and therefore represent well-established technology. Figure 1 shows a typical cyclone, which has the following components that need to be sized:

- The diameter of the feed chamber.

- The length of the inlet chamber.

- The length of the spigot section.

- The underflow spigot diameter.

- The length of the vortex finder.

- The diameter of the vortex finder.

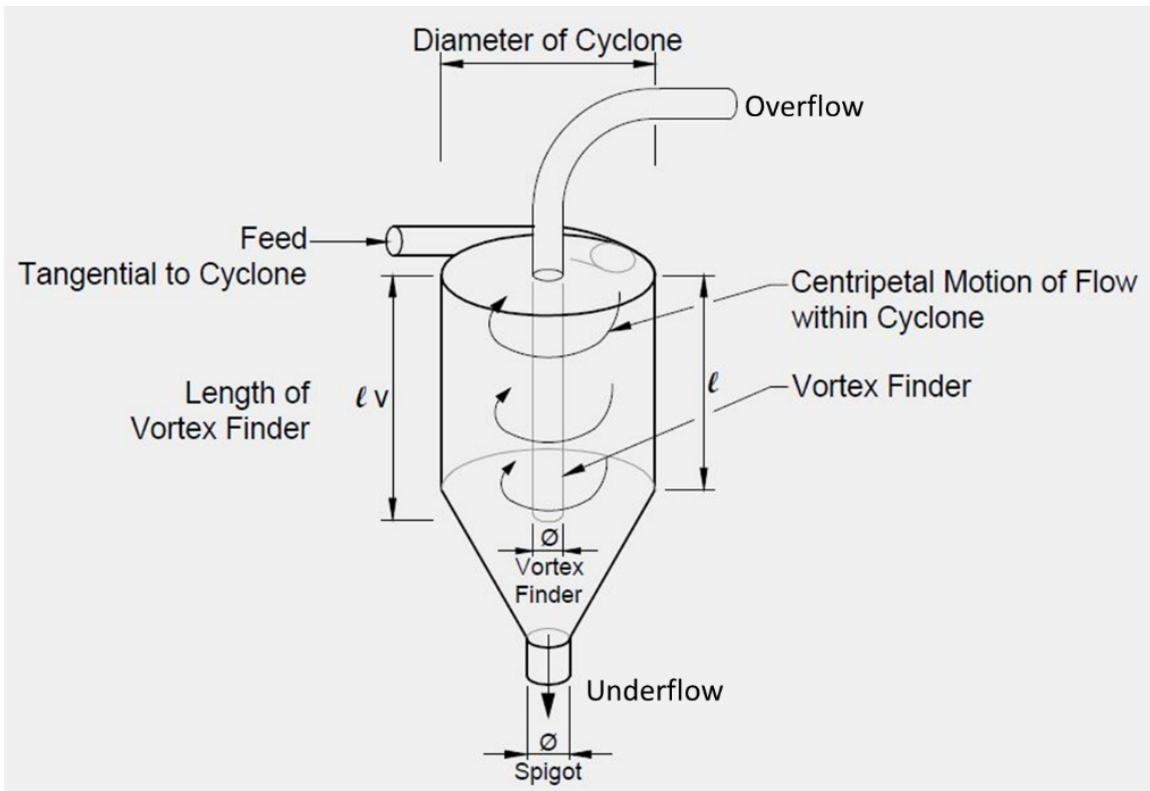

Figure 1 Typical cyclone details

Numerical modelling of cyclones to establish cyclone dimensions provides reasonable results adequate for preliminary sizing (Vakamalla \& Mangedoddy 2016) on the basis of which refinements to spigot sizes and vortex finder locations can be undertaken during pilot testing. Provided slurry properties, solids particle size distributions (PSD), flow rates and pressures remain constant, off-the rack cyclones from established manufacturers are reliable and require low maintenance. It is common to operate cyclones in nests with only some of the cyclones operating at any one time, thus allowing maintenance without disrupting operations. The use of nests also allows for greater variability in the feed as the number of cyclones operating at any time can be varied in accordance with the feed characteristics.

Cyclones can, however, also be used as dewatering units by applying a vacuum pressure to the spigot outlet. The vacuum is generated by the overflow and can be managed automatically through the application of a flexible flute attached to the underflow spigot. The cut size is less precise and the underflow generally coarser but if the objective is dewatering, the cut size is less critical.

The performance of cyclones is very dependent on the PSD and the rheology of the carrier fluid, including the effect of the fines fraction. However, at a feed concentration of $45 \%$ by weight for tailings with a solids specific 
gravity of 2.8, the underflow concentration would be between 74 and $78 \%$ solids and about $30 \%$ of the solids would report to the underflow. The overflow would require further treatment and the most common approach would be to use a thickener. In this event, the coarser cut size produced by a vacuum cyclone may be beneficial because the coarse particles in the overflow could improve the efficiency with which the overflow will be thickened. That is, they will tend to drag the flocculated particles down with them as they settle as well as entrain the flocs at the base of the thickener.

\section{$3 \quad$ Vibratory screens for dewatering}

Vibratory dewatering screens have been in use for many years predominantly in the dewatering of concentrates or the conditioning of slurries within the processing plant. Examples lie in a number of mineral processing plants in Peru and Chile. Their application to tailings dewatering is a logical extension and there are many operations around the world that apply this methodology with success. One such example is Mantos Blancos Mine in Chile. Vibratory screens comprise a screen that is sloped upwards from the feed. An oscillatory motion is induced into the cyclone that causes the slurry on the screen to be thrown forward. In this process, the separation of solids and liquids is enhanced with the solids releasing the liquids to flow through a sieve at the base of the screen. Cut sizes down to 25 microns are achievable (Schoepflin 2017). Figure 2 shows a typical vibratory screen.

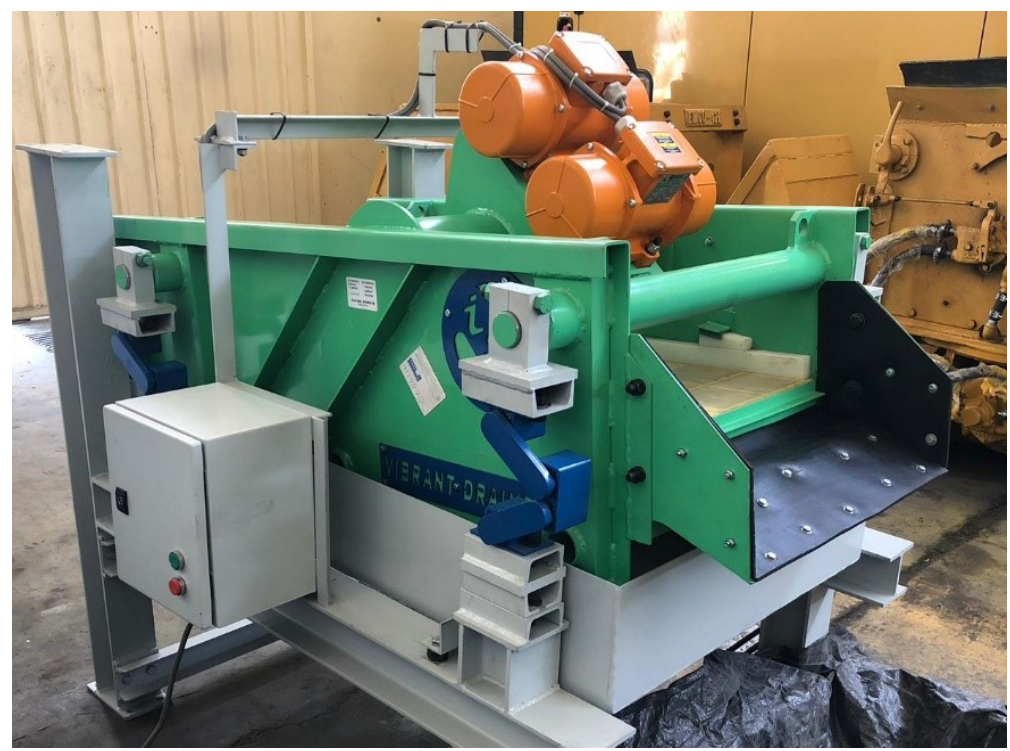

Figure 2 Typical vibratory dewatering screen arrangement (photo courtesy Dewatering Technologies Australia Pty Ltd)

The parameters that need to be optimised in specifying a vibratory dewatering screen are typically:

- The length of the screen.

- The angle of the screen.

- The oscillation frequency.

- The sieve opening size.

These parameters are determined through bench, semi-pilot and pilot-scale testing.

The material passing through the sieve at the base of the screen requires further treatment commonly through a thickener or a second screen with a finder sieve followed by a clarifier. By slightly oversizing the length of the screen, a significant variation in the feed in terms of slurry concentration can be accommodated and the feed concentration can be as low as $25 \%$ solids by weight. Provided the screens are suitably sized for the cyclone underflow material, clogging of the screen is low. Wear rates are manageable. 
By positioning a nest of cyclones ahead of the discharge onto the screen and discharging the underflow onto the screen, and then the overflow onto the underflow, the sieve size can be increased, and the efficiency of dewatering improved. In this event it is necessary to carry out the cyclone design as already discussed and optimise the cut and sieve sizes through bench, semi-pilot and pilot-scale testing.

\section{$4 \quad$ Other new technologies}

A dewatering method that is rapidly advancing following its initial development on coal tailings beginning in the 1970s is that of centrifuge decantation where water is removed by inducing a centripetal motion on the slurry while winding this forward using a form of Archimedes' screw. The decantation process is assisted by shaping the centrifuge barrel conically at the solids discharge end. A typical centrifuge arrangement is shown in Figure 3, which is reproduced from Klug et al. (2018).

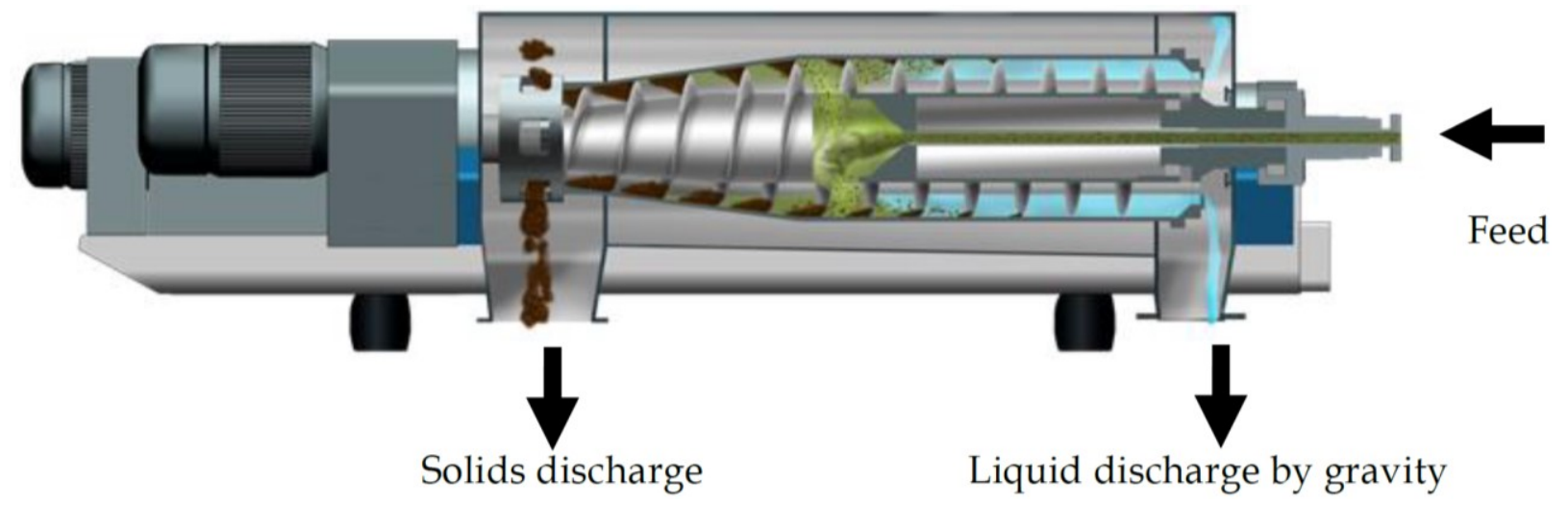

Figure 3 Typical centrifuge decanter arrangement (courtesy Flottweg SE)

Challenges to this approach that are steadily being overcome lie in the following:

- Abrasion by the tailings and resulting high wear rates.

- Energy requirements.

- The need to have a consistent feed.

\section{$5 \quad$ New but established technologies}

Over the past two decades, a number of newer dewatering technologies have undergone significant development and commercialisation and are now being applied on many mining operations worldwide. These are briefly described herein.

\subsection{Vacuum filtration using disc filters}

Steadily lowering manufacturing costs for ceramic filters have made the use of vacuum disc filters more viable. These filters comprise a bath of tailings that is continuously charged with slurry. A drum equipped with fins onto which filters are attached rotates the fins through the drum. A vacuum is applied to the fins and through the ceramic filters. While the fins are below the slurry level in the bath, the vacuum sucks tailings to the ceramic filters and draws water from the attached mass. Just before the rotating fin re-enters the bath, scrapers dislodge the solids that have been sucked against the ceramic filters. The scrapings fall onto a conveyor and are removed. Water recovered by the vacuum pumps is returned to the processing plant.

Production is determined by the vacuum pressure and the number and diameter of the fins equipped with ceramic filters. Commonly, several units are installed depending on the total tonnage. Tailings production is continuous. 


\subsection{Vacuum filtration using belt filters}

These filters comprise a continuous conveyor where the belt comprises specially designed layers of fabric capable of filtering the tailings. A vacuum is introduced below the upper layer of the belt. Slurry is discharged evenly onto the belt and, as the solids are drawn along the belt, the vacuum draws water from the solids through the belt. A scraper at the end of the conveyor removes the solids from the belt. These solids fall onto a normal conveyor and are removed.

Production rate depends on the vacuum pressure and the length of the belt. Several belts are usually installed, depending on the throughput requirements for the filtration plant. Tailings production is continuous. Pressure is limited to a practical vacuum determined by atmospheric pressure and the approach is therefore sensitive to altitude.

\subsection{Pressure filtration using filter presses}

The higher the pressure that can be applied to the slurry, the quicker the filtration process. Pressure filtration has evolved in order to overcome the practical limitation on vacuum generation set by the cavitation pressure of the water. Pressure filtration entails the application of positive pressure on the slurry. The slurry is pumped under pressure into sets of vertically stacked plates equipped with filter cloth. The pressure in the plates is increased and held to allow time for the pressure to force water through the fabric. When the plates are parted, the dried tailings fall onto a conveyor and are removed.

The production rate is dependent on the time for filtration to take place and a cycle time of 8-15 minutes is common. The number of plates (and the number of sets of plates) are set to ensure that the tailings are continuously being fed and discharged from the filtration plant.

\subsection{Filtration in combination with waste rock}

In recent years, research and development has yielded a process where filtered tailings are combined with waste rock to reach a dry consistency suitable for mechanical stacking. The absorbent capacity of the waste rock allows for a lower degree of filtration of the tailings. A number of operations are trialling this approach to verify its practicality as well as the geotechnical characteristics of the combined product. Issues to be considered in evaluating this approach are:

- Bringing the waste rock to a suitable size for conveying (i.e. crushing the waste rock).

- The effect of fluctuations in the water content of the feed slurry.

- The challenge of managing the mining and the processing operations such that both feeds are continuous.

\section{TSF design and management considerations}

\subsection{Hydraulically deposited tailings}

While slurry behaviour varies according to the mineralogy of the tailings at a given water content, generally slurries thickened to $<60 \%$ solids will require a water-containing TSF geometry where the crests are higher than the central part of the TSF and water is retained within the TSF. Deposition commences from the low ground and side slopes are generally constructed of compacted material. Typical examples are indicated in Figure 4. 

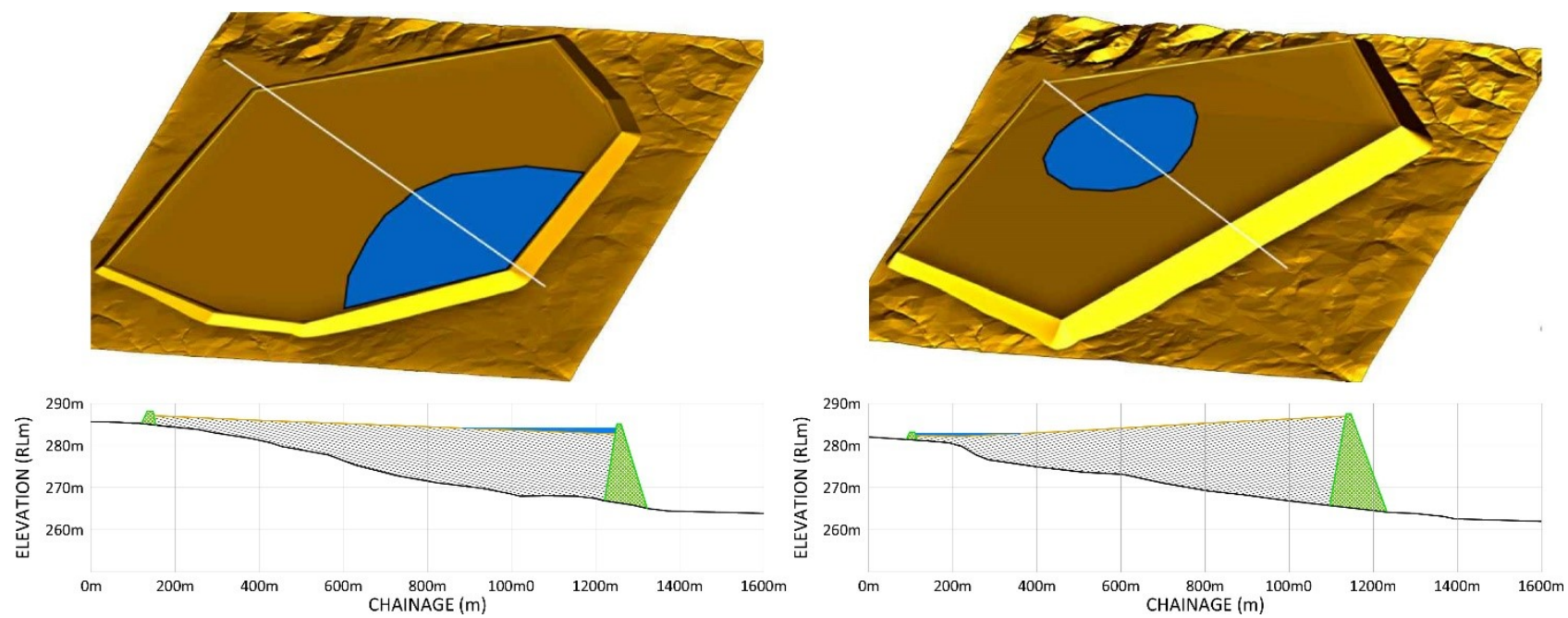

Figure 4 Typical examples of water-retaining tailings storage facilities (lengths in metres)

Issues to be addressed with these facilities, apart from dusting and surface and groundwater contamination, are:

- Slope stability (side slopes are generally steeper than 1:4 (vertical: horizontal)).

- Slope erosion during operation as well as at closure.

- Long-term management of the pond water, which will continue to retain rainwater over the long-term, water which will have potential energy and which, ultimately, will find its way to ground level.

A change to high-density slurry management can enable the formation of a water-shedding landform. In such a landform, deposition starts from the high ground with discharge towards the low ground with minimum starter embankment sizes around the perimeter and a lower main embankment since tailings are 'stacked' on the higher ground. Slopes are usually flatter than 1:25 (vertical: horizontal) and are generally low eroding. After covering to prevent contamination of the runoff water, as well as control dusting, the surface runoff water can be discharged to the environment with minimal long-term risk. Figure 5 shows typical examples of the types of high-density slurry TSF.
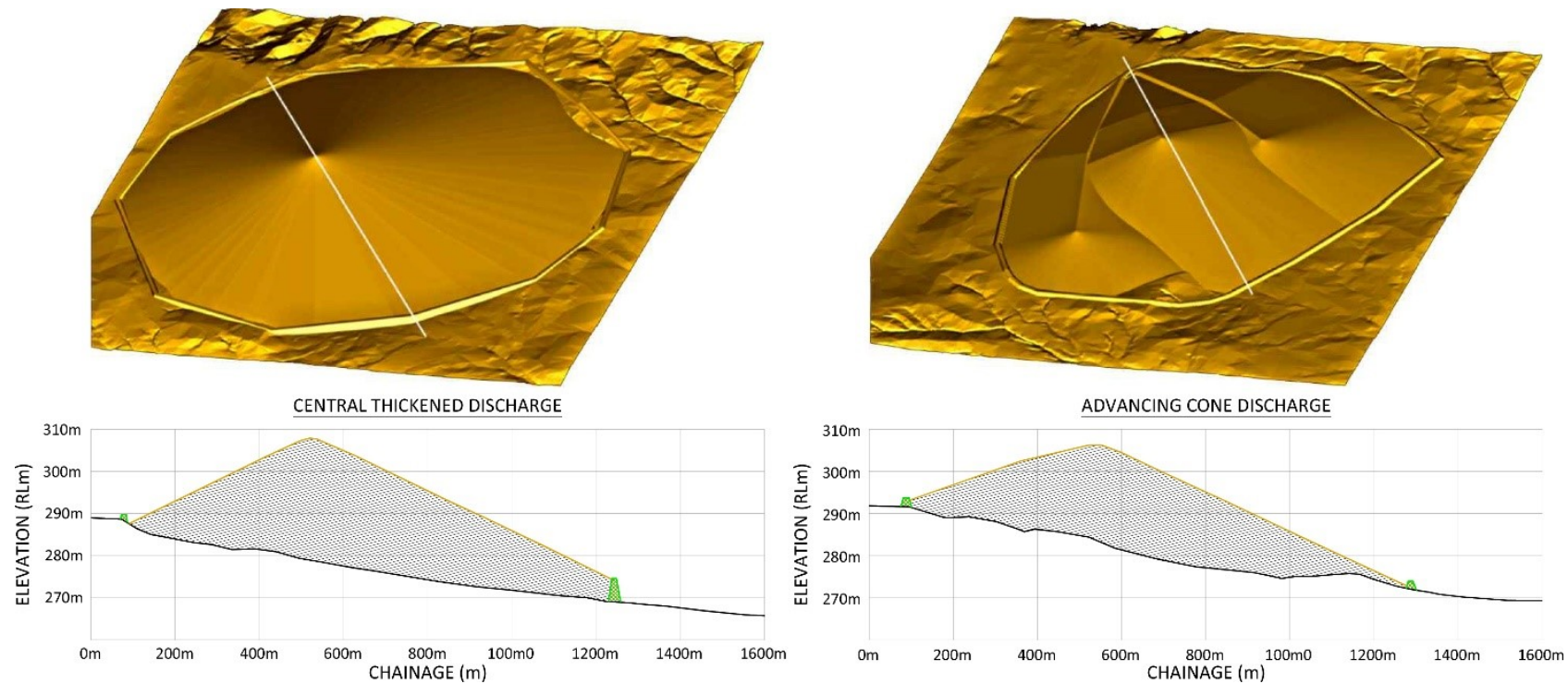

Figure 5 Typical examples of water-shedding tailings storage facilities (lengths in metres) 


\subsection{Dry deposited tailings}

'Dry' tailings management of tailings that are dewatered by whatever appropriate means (including those described in sections 2 to 5 in this paper) to the extent that it can be transported by conveyor, has been put forward by the investigators into the Mount Polley failure as one example of best available technology. This is because, in tandem with dewatering, there is an expectation that the placed tailings will be compacted and therefore will have a lower void ratio and higher shear strength than hydraulically placed tailings. This approach presents a number of challenges that need to be considered during the design:

- The requirement for dewatering to a water content close to the optimum moisture content of the tailings so as to maximise placed density. Placement of tailings above the optimum water content will result in lower density, higher void ratio and lower in situ shear strength tailings as well as a risk that the placed mass will saturate with continuous building, potentially generating high pore pressures with implications for slope stability.

- With finer tailings, it is vital to regulate the rate of placement of the tailings to ensure that excess water pressures are not generated in the tailings. Foundation consolidation rates are also a key consideration in this respect particularly if dry tailings are placed over existing deposits of fine hydraulically placed tailings. Even coarse tailings placed wet of optimum at high rates of rise can be susceptible to both static as well as seismic liquefaction.

- Dewatering to a consistent water content. Wide fluctuations in water content will complicate the compaction process and result in a non-homogeneous mass because of the varying compaction performance.

- Dust management. The tailings rapidly dry on arrival at the TSF and loose heaps of tailings are highly susceptible to dusting. The problem occurs whether tailings are placed with stackers or trucks. The stacker heaps are normally left untouched until the conveyor has moved well past the line of deposition before equipment can be brought in. Trucking has a similar problem, but dust is generated by the traffic.

In seismic areas, it will be essential to compact the outer zone of the TSF to near embankment quality levels since this zone will then provide high strength mass support to potentially variable tailings placed in the central parts of the TSF. It would be prudent to incorporate this approach into TSFs in low seismicity areas, particularly if there is a probability of significant variation in the dry tailings product as a result of mineralogical or processing variations that will exacerbate fluctuations in the water content and density of the placed tailings. Such a design is illustrated in Figure 6 . The lower compacted tailings are tailings that have been nominally compacted by equipment movement as they are confined by the compacted tailings.

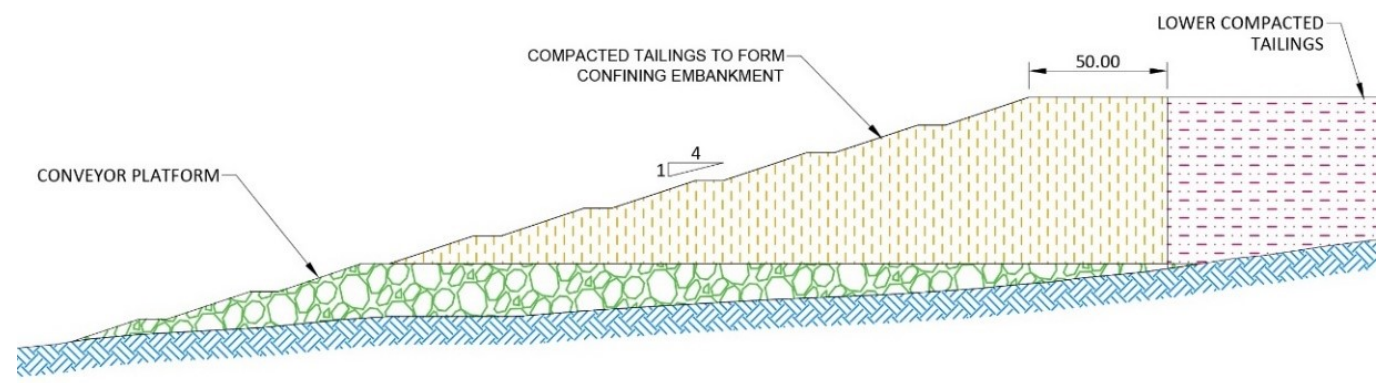

Figure 6 Typical section through a 'dry' disposal tailings storage facility showing compacted outer embankment 


\section{$7 \quad$ Operating and capital costs}

The tailings management considerations already briefly described will provide an indication of the target water content of the tailings product to be sent to the TSF. The issues addressed in containing the risks posed by TSF management and closure will provide the sustainable cost band within which the tailings operations as whole need to fit. Costs need to be divided into four main activities:

- Dewatering to a given tailings water content.

- Transport to and around the TSF.

- TSF operation encompassing placement of the tailings and raising of the TSF.

- TSF decommissioning, closure and, hopefully, relinquishment.

There will need to be detailed trade-off studies for each project in which the above activities are considered as the tailings, production rates, site conditions, water management, and regulatory/governance constraints will be project specific and client specific. Broadly speaking, the more extensive the dewatering requirement, the higher will be the capital and operating costs but, within reason, the lower will be the risks associated with managing and closing the TSF. This author's experience is that the 'sweet spot' usually lies in highdensity slurry management with slurry consistencies in the range $63-67 \%$ solids, depending on the rheological characteristics of the slurry. At this water content, the trade-off between water savings, capital and energy costs, and the ability for the tailings to flow into place with minimal supernatant water release, together with the formation of a water-shedding landform, strikes the optimal balance. This optimal balance can be achieved provided rates of rise of the tailings are in line with the consolidation of the tailings and the drying potential offered by the site location.

\section{Conclusion}

A range of dewatering methods that form an alternative to thickening and filtration, and which are particularly suited to small and medium mining operations, have been presented and discussed. These can offer lower cost, more robust approaches to dewatering and merit serious consideration together with the appropriate method of TSF operation. Costings should consider not only the capital and operating cost of the dewatering system but also the cost of transportation, distribution and spreading the tailings as well as the cost of reshaping and covering the tailings landform to closure requirements.

\section{References}

Klug, R, Rivadeneira, A \& Schwartz, N 2018, 'Dewatering tailings: rapid water recovery by means of centrifuges', Proceedings of the 5 th International Seminar on Tailings Management, Gecamin, Santiago.

McPhail, GI 2015, 'Thickening plant concepts', in RJ Jewell and AB Fourie (eds), Paste and Thickened Tailings - A Guide, 3rd edn, Australian Centre for Geomechanics, Perth.

Schoepflin, K 2017, 'Mines in water-scarce areas turn to dewatering screens', Modern Mining, March, pp. 30-31.

Vakamalla, TR \& Mangadoddy, M 2016, 'Numerical simulation of industrial hydrocyclones performance: role of turbulence modelling', Separation and Purification Technology, vol. 176, pp. 23-39. 
